\section{Caracterização macroscópica e microscópica da pododermatite em relação à classificação industrial de pés de frango para consumo humano}

[Pododermatitis macroscopic and microscopic characterization related to industrial classification of chicken feet for human consumption]

V.Q. Teixeira ${ }^{1}$, F.F. Santos ${ }^{2 *}$, M.H.C. Aquino ${ }^{1}$, R. Tortelly ${ }^{1}$, E.R. Nascimento ${ }^{1}$, V.L.A. Pereira ${ }^{1}$

${ }^{1}$ Universidade Federal Fluminense - Niterói, RJ

${ }^{2}$ Instituto Federal de Educação, Ciência e Tecnologia do Amazonas - Manaus, AM
F.F. Santos https://orcid.org/0000-0002-0684-3709 V.Q. Teixeira https://orcid.org/0000-0002-5369-139X M.H.C. Aquino https://orcid.org/0000-0002-5906-8101 R. Tortelly https://orcid.org/0000-0002-4431-6635 .R. Nascimento https://orcid.org/0000-0003-2316-8933 h.L.A. Pereira https://orcid.org/ 0000-0003-2197-8916

\title{
RESUMO
}

O presente trabalho teve como objetivo identificar e classificar a pododermatite em frangos de corte, comparando as lesões microscópicas com os aspectos macroscópicos utilizados pela inspeção sanitária. Foi realizada coleta de pés de frangos de corte, em matadouro de aves sob inspeção sanitária, após classificação utilizada nos padrões para exportação. Foram coletados 30 pés tipo A, 30 pés tipo B e 33 pés tipo C, escolhidos aleatoriamente dentro de cada grupo. Para análise histopatológica, foram desenvolvidos escores de acordo com a gravidade das lesões, variando de 0 a 2. Foi observada associação (qui-quadrado, $\mathrm{P}<0,05)$ entre a classificação macroscópica $(\mathrm{A}, \mathrm{B}$ e $\mathrm{C})$ e as alterações histológicas $(0,1$ e 2). A classificação A diferiu significativamente (ANOVA, Tukey-Kramer, $P<0,05$ ) das classificações $B$ e C quanto aos escores histopatológicos observados. Não houve diferença no comprometimento dos pés pelas lesões que justificassem a separação entre os pés classificados em B e C, uma vez que ambos apresentaram delimitação linear das lesões, sugerindo superficialidade e restrição ao epitélio queratinizado. Portanto, sugere-se o aproveitamento dos pés para consumo humano após remoção mecânica do "calo de pé”, uma vez que este produto não oferece riscos ao consumidor.

Palavras-chave: frango, dermatite, histopatologia, pata, cortes

\begin{abstract}
The aim of this study was to identify and classify pododermatitis in broilers, comparing the microscopic lesions with the macroscopic aspects used by the Sanitary Inspection. Broiler chicken feet were collected at a Poultry slaughterhouse under Sanitary Inspection, after classification according to the exportation standards. The chicken feet were randomly selected in each group, 30 feet type A, 30 feet type B and 33 feet type $C$. For the histopathological analysis, scores were developed according to the severity of the lesions, varying from 0 to 2. There was association (Chi-square, $P<0.05$ ) between the macroscopic classification (A,B and $C$ ) and histological changes (0, 1 and 2). The A classification differed significantly (ANOVA, Tukey-Kramer, $P<0.05)$ from the $B$ and $C$ classifications regarding the histopathological scores observed. There was no difference in feet lesions that justified the separation between the feet classified in $B$ and $C$, since both presented a linear delimitation of the lesions, suggesting superficiality and restriction to the keratinized epithelium. Therefore, the use of the feet for human consumption after mechanical removal of the footpad lesions is suggested since the product does not pose risks to the consumer.
\end{abstract}

Keywords: chicken, dermatitis, histopathology, paw, parts

Recebido em 25 de fevereiro de 2018

Aceito em 8 de outubro de 2018

*Autor para correspondência (corresponding author)

E-mail: felipefaccini@hotmail.com 


\section{INTRODUÇÃO}

A indústria avícola está em constante busca por inovações, com o objetivo de se adequar às preferências dos consumidores. A apresentação da carne de frango na forma de cortes responde por uma faixa cada vez maior do mercado. A produção de cortes de frango é interessante tanto pelo ponto de vista dos consumidores, devido à sua praticidade, como das indústrias, devido ao maior valor agregado. Os pés de frango são cortes de grande importância comercial para os países asiáticos, embora para a maioria dos demais países sejam considerados subprodutos (Bean et al., 2007; Tavares et al., 2010).

A produção de pés de frango como cortes para consumo humano agrega, portanto, expressivos valores a esses produtos, principalmente com relação aos países ocidentais. Foi pago US\$0,67 por quilo de pés produzidos nos EUA, enquanto para os demais cortes, como asas e coxas, foram pagos US $\$ 0,84$ e US $\$ 0,95$, respectivamente, em 2017. Apesar dos menores valores pagos pelos pés, o valor pago é muito superior ao que seria remunerado no país de origem, cujo destino é a graxaria (USDA, 2018). O produto brasileiro possui destaque e maior valor agregado, pois classifica manualmente os pés e consegue se adequar melhor às exigências de classificação. Além disso, a umidade é consideravelmente menor por conseguir separar o gelo usado no resfriamento do produto durante classificação (Bean et al., 2007). Considerando-se o terceiro trimestre de 2017, enquanto a média de preço para exportação do Brasil de carcaças de frango ficou em US\$1,08, o preço dos pés exportados para a China foi de US\$2,18. Esses preços são comparáveis ao melhor mercado de exportação brasileiro, a Europa, que pagou por produtos nobres, como peito de frango, e por produtos processados US\$2,34 e US\$2,35, respectivamente (Mulder, 2018).

Apesar do crescimento da produção interna, a oferta de pés de frango na China ainda é deficiente, deixando uma lacuna no mercado consumidor. Essa deficiência resultou em aumento súbito e progressivo nas importações do produto. Com isso, padrões mais rigorosos para esses produtos foram adotados, com o objetivo de levar ao consumidor chinês um produto de melhor qualidade (Bean et al., 2007). China, incluindo Hong Kong, é a maior importadora mundial de pés de frango. Somente esse produto representou $62,1 \%$ do total de produtos de frango importados pelo país. O Brasil tem uma posição de destaque no fornecimento, tendo sido o maior exportador desse produto para a China, correspondendo a $55,2 \%$ do total importado em 2010 (Woosley et al., 2011).

O produto pé de frango é classificado comercialmente, de acordo com exigências de mercados compradores, em três especificações: tipo A, pés de melhor qualidade, que não apresentam lesão alguma; tipo B, de segunda qualidade, que apresentam lesões limitadas em sua extensão; tipo $C$, pés com lesões extensas, portanto não comestíveis e destinados à graxaria. De acordo com o anexo IX da Portaria $\mathrm{N}^{\mathrm{O}} 210$ do Ministério da Agricultura, Pecuária e Abastecimento (Mapa), a pododermatite está enquadrada, dentro dos critérios e destinos de aves, como dermatoses, sendo, pois, uma lesão de caráter condenatório da região atingida ou de todo o pé (Brasil, 1998). Assim, o Mapa somente considerava próprios para consumo humano os pés classificados como tipo A pela indústria e, por conseguinte, não permitia registro e certificação de classificações relativas a "tipo" ou "grade".

Os padrões de Hong Kong permitiam a entrada de produtos classificados como "não próprios para consumo humano", dessa forma, os pés tipo B eram exportados com pet food. No entanto, em 2005, esses padrões foram unificados, com exigência chinesa de que os pés fossem inspecionados. Portanto, com a unificação dos padrões, os países poderiam exportar pés dos tipos A e B, desde que inspecionados (Bean et al., 2007). Entretanto, por considerar tratar-se de produtos não comestíveis, o entendimento do Mapa era de não permitir a comercialização dos pés tipo B. Posteriormente, foi publicada a Circular $\quad N^{\circ}$ 599/2010/CGPE/DIPOA, que permitia a comercialização destes pés, desde que atendidas algumas condições higiênico-sanitárias (Brasil, 2010).

A pododermatite é um tipo de dermatite de contato que atinge o coxim plantar das aves, podendo acometer também os coxins digitais. Sua evolução é caracterizada por descoloração da pele, hiperqueratose, erosões e, nos casos mais graves, úlceras (Santos et al., 2002; Crespo e Shivaprasad, 2003). Essas lesões acarretam 
problemas locomotores nas aves, de forma a restringir seu acesso ao alimento e à água, o que retarda seu desenvolvimento e compromete o bem-estar dos animais. Fatores relacionados ao manejo, como alta umidade da cama, alta densidade dos plantéis, tipo de criação e deficiência de biotina, podem predispor à pododermatite (Crespo e Shivaprasad, 2003).

As lesões de pododermatite são objeto de estudo há mais de 30 anos, no entanto grande parte dos trabalhos estudam as causas do seu aparecimento e caracterização das lesões (Nairn e Watson, 1972; Martland, 1985; Greene et al., 1985; Santos et al., 2002; Bilgili, 2009; Kyvsgaard et al., 2013) ou a utilizam como medida de avaliação do bem-estar animal (Berg, 2004; Pagazaurtundua e Warris, 2006; Lorm et al., 2009; Vanderhasselt et al., 2013). Os aspectos relativos à saúde e qualidade dos pés e patas em relação à inspeção sanitária, como produto destinado ao consumo humano, foram pouco estudados. $\mathrm{O}$ presente trabalho teve como objetivo identificar e classificar a pododermatite em frangos de corte, comparando as lesões microscópicas com os aspectos macroscópicos que determinam a classificação desses pés no processamento tecnológico do produto para consumo humano.

\section{MATERIAL E MÉTODOS}

Foram utilizados 93 pés de frangos de um mesmo lote, com 50 dias de idade, obtidos em matadouro-frigorífico de Minas Gerais fiscalizado pela inspeção federal. Os pés foram coletados após a etapa de resfriamento, em "chiller" próprio, onde atingiram a temperatura de $7^{\circ} \mathrm{C}$ no interior do produto. Os pés foram classificados, conforme as características macroscópicas do coxim plantar, seguindo os padrões utilizados para exportação e padrões utilizados por países europeus para avaliação do bem-estar dos animais nas plantas de abate (Lorm, 2009). Assim, os pés de frangos foram classificados em três tipos: A - sem lesão, aparentemente íntegros, sem alteração da camada córnea; B - lesões brandas, presença de edema e descamação da camada córnea; $\mathrm{C}$ - lesões graves ou múltiplas, descamação intensa da camada córnea, acúmulo de material orgânico, focos de necrose. Foram coletados, então, 30 pés de frango tipo A, 30 pés tipo B e 33 pés tipo $C$, os quais foram transportados sob refrigeração ao laboratório.

Para o exame histopatológico, os pés foram submersos em solução tamponada de formol a $10 \%$. Esse material foi processado pelas técnicas rotineiras de histopatologia e corado por HE. Para a análise histopatológica, foram desenvolvidos escores que variavam de 0 a 2 , de acordo com as alterações observadas: 0 - aspecto normal do órgão; 1 - presença de úlcera ou restos celulares, infiltrado inflamatório e/ou nódulos linfoides; 2 - presença de úlcera ou restos celulares, infiltrado inflamatório e ausência de nódulos linfoides perivasculares. Foi realizada análise de frequência pelo teste de quiquadrado $\left(\chi^{2}\right)$ para avaliar se houve associação entre a classificação macroscópica e os escores histopatológicos. Análise de variância (ANOVA) seguida do teste de Tukey-Kramer foram utilizados para avaliar as médias dos escores histopatológicos obtidas nas classificações macroscópicas (Thrusfield, 1995).

Para avaliar a contaminação do produto classificado como tipo C, condenado na inspeção sanitária por apresentar as lesões mais severas, foram selecionados 23 pés para o exame microbiológico. Foram realizadas desinfecção externa com álcool a $70 \%$ e uma incisão transversal sobre a área lesada, com o auxílio de bisturi estéril, para coleta do material no interior da lesão. Esse material foi macerado e uma alíquota foi semeada em ágar Colúmbia (Merck $^{\circledR}$, Alemanha) suplementado com 5\% de sangue de ovino (AS), ágar "Eosin Methylene Blue" (Difco ${ }^{\circledR}$, EUA) (EMB) e caldo "Brain Heart Infusion" (Merck ${ }^{\circledR}$, Alemanha) (BHI). Após incubação a $37^{\circ} \mathrm{C}$ por 24 horas, foram observadas as características morfotintoriais do crescimento bacteriano e foi feita identificação por meio de testes bioquímicos (Downes e Ito, 2001).

\section{RESULTADOS E DISCUSSÃO}

Pela análise macroscópica, nos pés do tipo A, foi observada descoloração do coxim plantar de 17 em amostras (Fig. 1A). Nos pés tipo B, a presença de pododermatite foi caracterizada pelo espessamento da pele nos coxins plantares, e observou-se a presença de úlceras circulares de diâmetro entre seis e 22 milímetros, com crostas de tonalidade acastanhada na periferia da lesão 
(Fig. 1B). Nos pés tipo C, as lesões foram mais severas, com múltiplas úlceras de diâmetro variando entre oito e 27 milímetros nos coxins plantares, com presença de lesões também nos coxins digitais e presença de camada de queratina aderida aos focos de necrose (Fig. 1C). Variações no tipo de lesão macroscópica em aves de mesma idade e pertencentes ao mesmo lote também foram relatadas por outros pesquisadores (Nairn e Watson, 1972; Martland, 1985; Greene et al., 1985; Bilgili et al., 2009). Foram observados desde coxins plantares íntegros até pés com extensas áreas de erosões e úlceras, significando que não há uniformidade no aparecimento dessas lesões em lotes de frangos de corte.

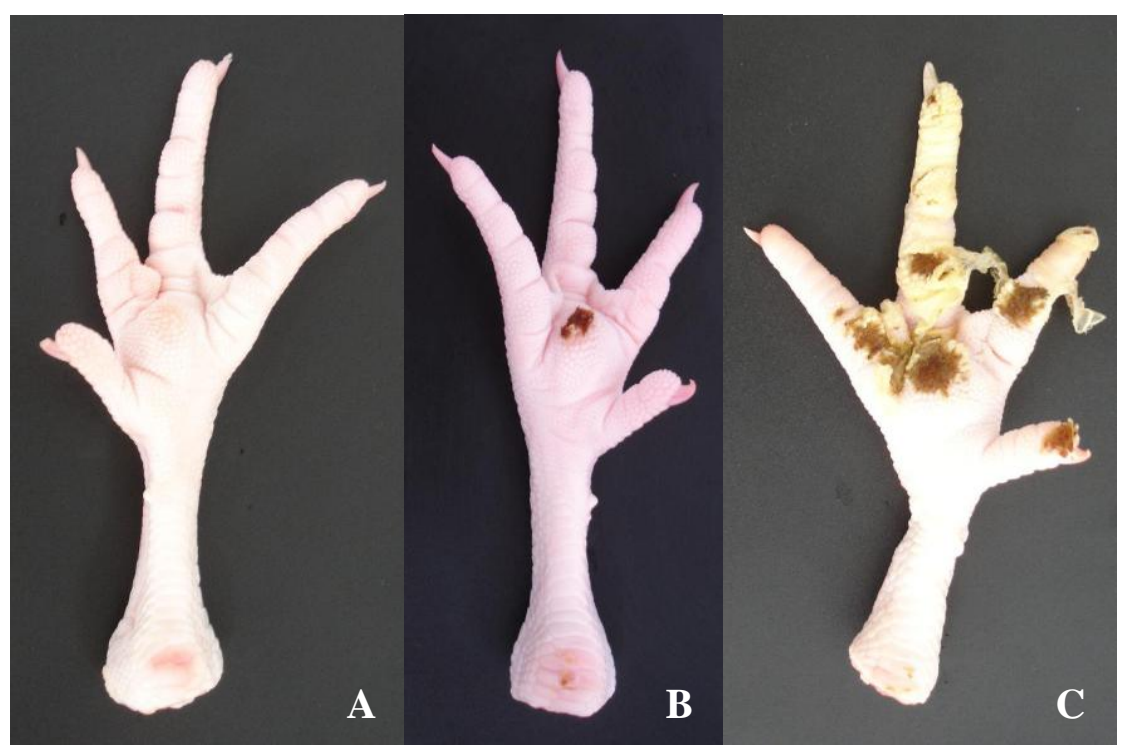

Figura 1. A. Pé de frango de corte com classificação tipo A. B. Pé de frango de corte com classificação tipo B. C. Pé de frango de corte com classificação tipo C.

Microscopicamente, ao se examinarem os pés do tipo A, foram identificados nódulos linfoides perivasculares com grande frequência (26/30) (Fig. 2A). Estes variaram em tamanho e quantidade, caracterizando o aspecto normal do órgão. Lesões microscópicas foram observadas em $20 \%$ dos pés, com aspecto linear na área de transição com tecido normal e alguns casos com destruição da queratina e presença de restos celulares associados à necrose do epitélio (Fig. 2B). Em outros casos, foi observada moderada resposta inflamatória mononuclear e a presença de granulócitos que mostravam distribuição difusa.

As lesões observadas em pés do tipo $\mathrm{C}$ em muito se assemelharam às lesões observadas nos pés tipo $\mathrm{B}$, apresentando agravos superficiais e não se aprofundando além do epitélio. As áreas de necrose foram mais severas, devido à sua extensão. A resposta inflamatória apresentou-se também de forma linear, mas os nódulos linfoides já não foram tão frequentes à observação microscópica. Um caso de trombose com destruição vascular foi identificado, associado a uma intensa reação inflamatória junto à área de necrose (Fig. 4). Foi encontrada infiltração superficial difusa de heterófilos, sendo a resposta inflamatória da lesão limitada à junção derme/epiderme, mesmo nos casos mais graves. Os pés tipo B apresentaram lesões mais severas que as do tipo A. Os nódulos linfoides estavam próximos a áreas de restos celulares, em alguns casos hiperplásicos e apresentando áreas de confluência (Fig. 3A). Extensas áreas de necrose apareceram com maior frequência, mas sempre mantendo o aspecto linear das lesões. Regiões focais de necrose foram também observadas. Nos casos mais severos de pododermatite ulcerativa, observou-se resposta inflamatória mista com raros granulócitos na base da lesão e disposição em paliçada de histiócitos e múltiplas células gigantes (Fig. 3B). Em um único caso, observouse o aprofundamento da lesão até a derme, com a presença de elementos linfoides entre os adipócitos. 


\section{Caracterização macroscópica...}

Houve uma tendência de redução no número dos nódulos linfoides perivasculares dos escores A para C. A presença de infiltrado inflamatório estava diretamente associada ao aparecimento de restos celulares e úlceras (Tab. 1).

As características macroscópicas e microscópicas dos pés tipo $\mathrm{A}, \mathrm{B}$ e $\mathrm{C}$ foram similares às encontradas no estudo de Santos et al. (2002) em frangos de corte aos 13, 20 e 45 dias, respectivamente. Embora esses pesquisadores tenham estabelecido uma relação cronológica com a gravidade das lesões, o presente estudo demonstrou que diferentes graus de lesão podem ocorrer em animais provenientes de um mesmo lote na idade de abate.

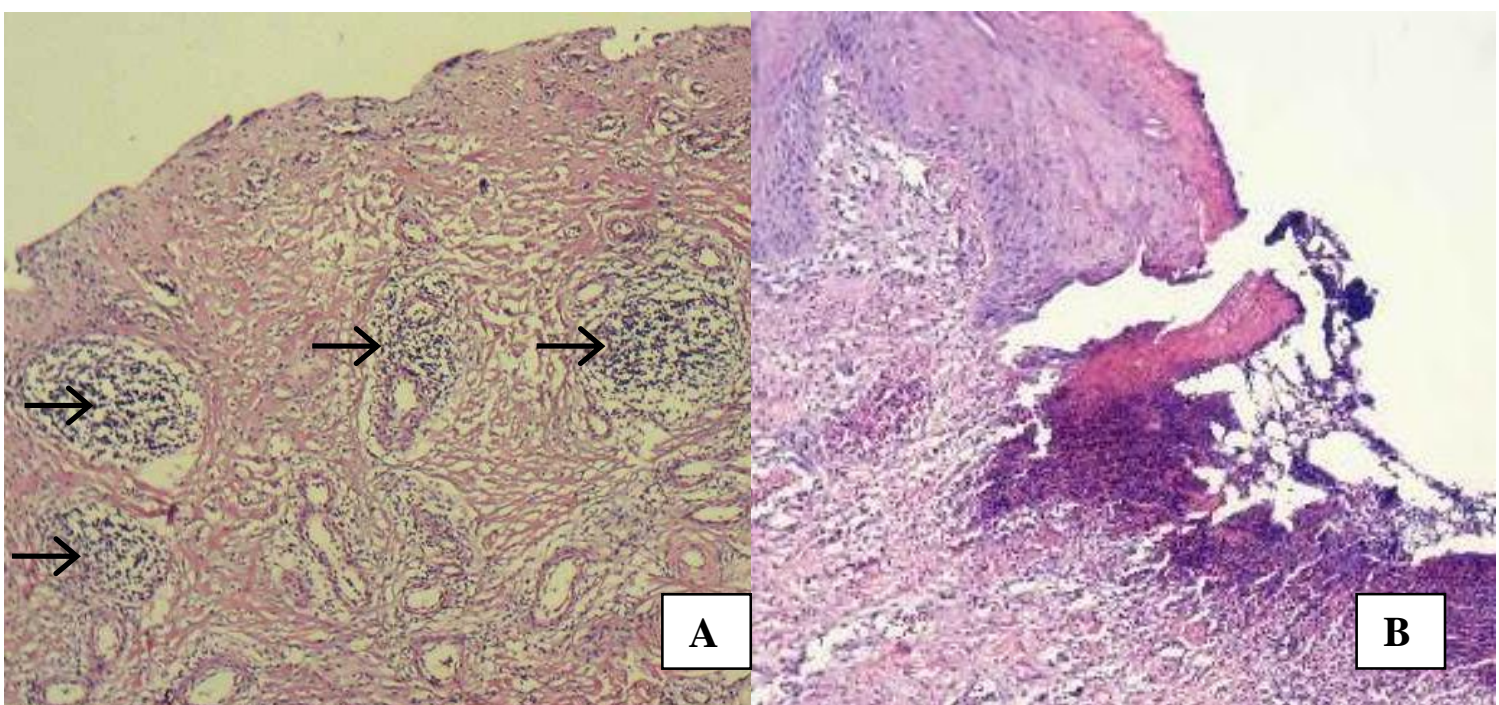

Figura 2. Pé tipo A de frango de corte. HE. Aumento: 40x. A. Múltiplos nódulos linfoides perivasculares (seta). B. Área de transição entre o epitélio normal e úlcera rica em restos celulares com discreta reação inflamatória na periferia da lesão.

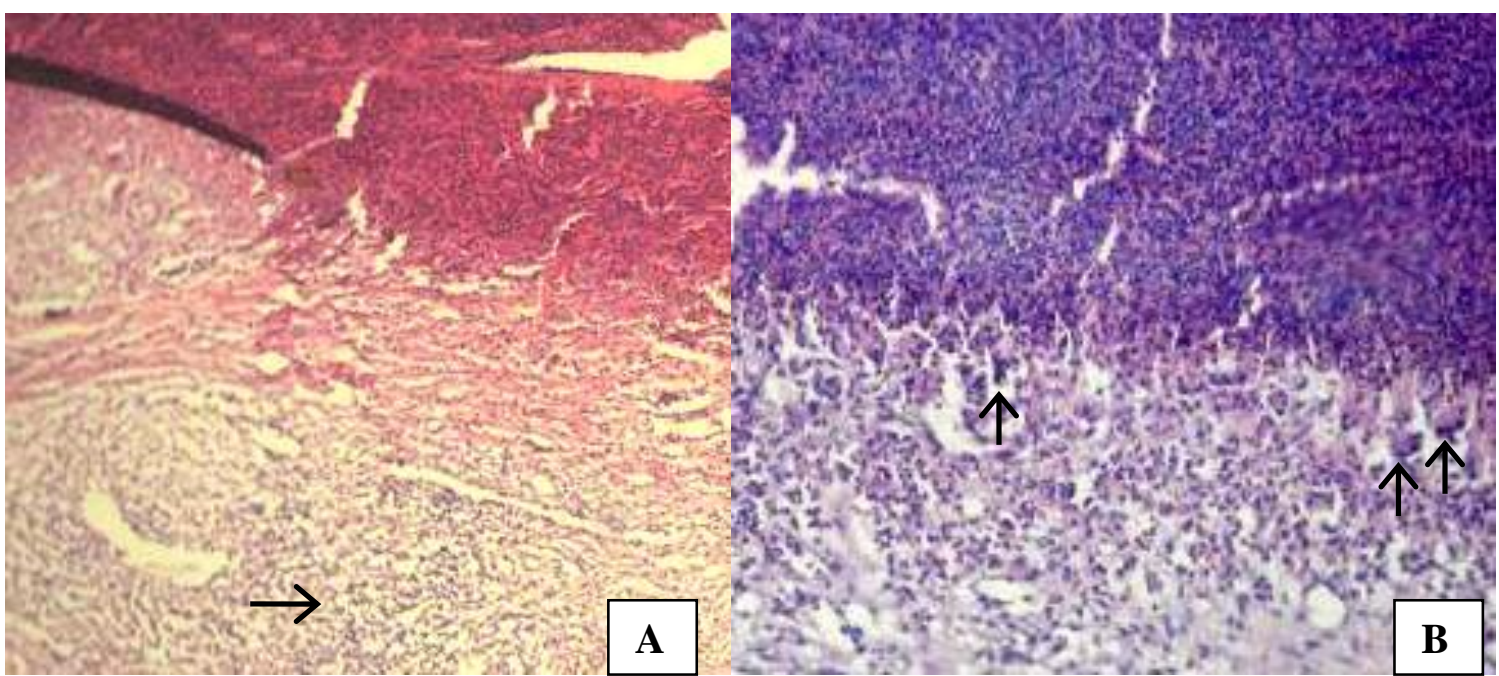

Figura 3. Pé tipo B de frango de corte. HE. A. Pododermatite ulcerativa. Nódulos linfoides perivasculares com área em confluência (seta) na base do processo ulcerativo. Aumento: 40x. B. Reação inflamatória mista com predominância de granulócitos com múltiplas células gigantes multinucleadas junto à necrose (setas). Aumento: 100x. 


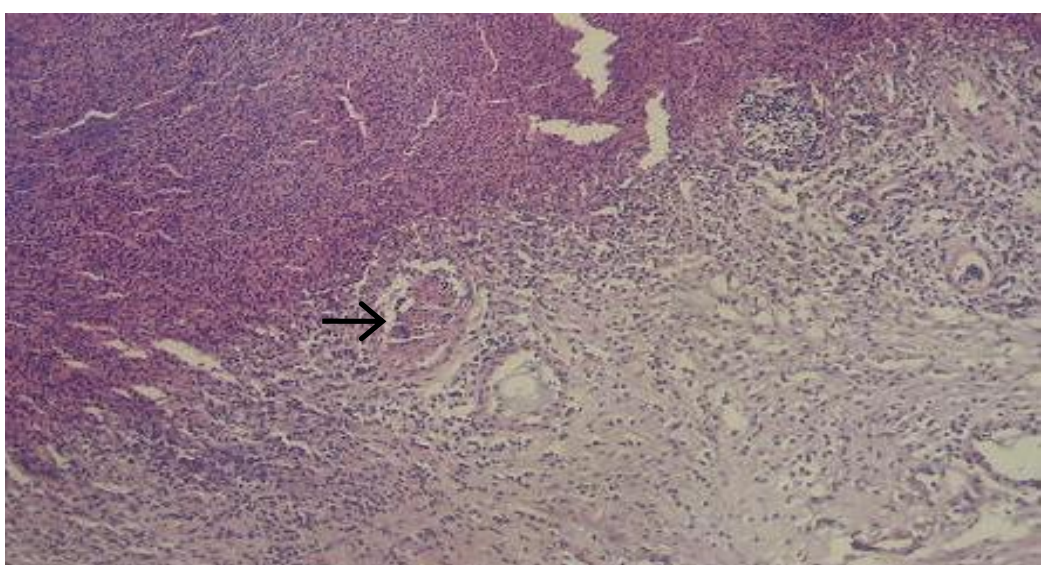

Figura 4. Pé tipo C de frango de corte. HE. Aumento: 100x. Pododermatite ulcerativa. Destruição vascular e trombose (seta) associada à intensa reação inflamatória junto à necrose.

Tabela 1. Achados histopatológicos distribuídos por classificação macroscópica de pés de frangos de corte

\begin{tabular}{lccc}
\multicolumn{1}{c}{ Achado histopatológico } & \multicolumn{3}{c}{ Classificação } \\
\hline Nódulos linfoides & A & B & $9(27 \%)$ \\
Infiltrado inflamatório & $26(87 \%)$ & $20(67 \%)$ & $28(85 \%)$ \\
Infiltrado de granulócitos & $11(37 \%)$ & $29(97 \%)$ & $2(6 \%)$ \\
Úlcera/restos celulares & $2(7 \%)$ & $3(10 \%)$ & $28(85 \%)$ \\
Trombose & $6(20 \%)$ & $29(97 \%)$ & $1(3 \%)$ \\
\hline
\end{tabular}

É importante ressaltar que todas as classificações macroscópicas, quando avaliadas pela microscopia, apresentaram um aspecto de delimitação linear das lesões, sem aprofundamento, além de não apresentarem contaminação bacteriana evidente. Isso evidencia a superficialidade da lesão e uma restrição junto ao epitélio queratinizado do pé. Portanto, seria possível o aproveitamento de pés tipo $\mathrm{B}$ e até mesmo tipo $\mathrm{C}$ para o consumo humano, desde que retirada a lesão, uma vez que, após a remoção, o produto não apresentaria grandes alterações.

Pelo teste de qui-quadrado, houve associação $(\mathrm{P}<0,05)$ entre a classificação macroscópica utilizada no processamento tecnológico (A, B e C) e as alterações histológicas (escores 0,1 e 2) dos pés de frango estudados (Tab. 2).

Pelo teste de ANOVA seguido do teste de Tukey-Kramer, houve diferença significativa $(\mathrm{P}<0,05)$ entre os escores histopatológicos observados nas classificações macroscópicas. A classificação A diferiu $(\mathrm{P}<0,05)$ das classificações B e C $(\mathrm{P}>0,05)$, mas não houve diferença entre B e C (Tab. 3). Dessa forma, histologicamente, não houve diferença no comprometimento dos pés pelas lesões que justificasse a separação entre os pés tipo B dos pés tipo C. Portanto, há possibilidade da remoção das lesões dos pés tipo B e C para seu aproveitamento, uma vez que as diferenças se limitam ao aspecto macroscópico.

$\mathrm{Na}$ avaliação microbiológica de 23 amostras de pés tipo C, a partir de 18 amostras $(78,26 \%)$ foi obtido crescimento bacteriano após o enriquecimento em caldo BHI. No entanto, no plaqueamento direto foi observada contaminação bacteriana insignificante. Bactérias Gram negativas foram isoladas de oito amostras e identificadas presuntivamente como enterobactérias. Staphylococcus spp. e Streptococcus spp. foram isolados de três amostras e Enterococcus spp. de seis amostras. Apenas em três amostras foi observado mais de um tipo de morfologia colonial. Pelos achados histopatológicos, não foi observada a presença de bactérias nos cortes analisados, o que sugere que a presença de bactérias nas lesões resultou de contaminação secundária não associada à lesão. 
Tabela 2. Associação entre os escores de alterações histológicas e a classificação macroscópica utilizada no processamento tecnológico de pés de frangos de corte

\begin{tabular}{lccc} 
& \multicolumn{3}{c}{ Classificação } \\
Escore histológico & $\mathrm{A}$ & $\mathrm{B}$ & $\mathrm{C}$ \\
\hline 0 & 23 & 1 & 5 \\
1 & 6 & 19 & 7 \\
2 & 1 & 10 & 21 \\
Total & 30 & 30 & 33 \\
\hline
\end{tabular}

$\chi^{2}, \mathrm{P}<0,05$.

Tabela 3. Classificação macroscópica em relação aos escores histopatológicos de pés de frango de corte sob inspeção sanitária

\begin{tabular}{lcccc} 
Classificação & $\begin{array}{c}\text { Número de } \\
\text { amostras }\end{array}$ & Média & Desvio-padrão & Mediana \\
\hline A & 30 & $1,27^{\mathrm{a}}$ & 0,52 & 1,00 \\
$\mathrm{~B}$ & 30 & $2,30^{\mathrm{b}}$ & 0,53 & 2,00 \\
$\mathrm{C}$ & 33 & $2,48^{\mathrm{b}}$ & 0,75 & 3,00 \\
\hline
\end{tabular}

ANOVA; Tukey-Kramer, $\mathrm{P}<0,05$; letras iguais não diferem entre si.

Outros pesquisadores verificaram a baixa contaminação microbiana desses produtos. Santos et al. (2011) avaliaram o efeito do processamento na contaminação dos pés de frangos de corte e verificaram que, devido a características que diferem do processamento de carcaças, como escaldagem a temperaturas mais elevadas, remoção da cutícula e rápido resfriamento, o processamento de pés promove uma grande redução da carga microbiana. Esses pesquisadores obtiveram resultados com números tão baixos quanto $3,7 \log _{10} \mathrm{UFC} / \mathrm{g}$ de bactérias aeróbias mesófilas, $0,6 \log _{10} \mathrm{MPN} / \mathrm{g}$ de coliformes totais e $0,4 \log _{10} \mathrm{MPN} / \mathrm{g}$ de coliformes termotolerantes. Brizio et al. (2013) obtiveram os valores de 3,6; 3,1 e 2,3 $\log _{10} \mathrm{UFC} / \mathrm{g}$ e $\mathrm{MPN} / \mathrm{g}$, respectivamente. Cho et al. (2016) analisaram pés produzidos na Coreia do Sul e encontraram valores similares, com 4,5; 3,0 e 1,8 $\log _{10} \mathrm{UFC} / \mathrm{g}$ e MPN/g, respectivamente. Portanto, estes são valores abaixo dos preconizados como seguros para cortes in natura de frango e, assim, o consumo de pés de frango apresenta um baixo risco microbiológico.

\section{CONCLUSÕES}

Os achados microscópicos corresponderam à classificação macroscópica dos pés de frangos utilizada nos matadouros avícolas, reforçando os critérios da indústria de classificação no processamento tecnológico. A remoção mecânica do "calo de pé" tem potencial para uso no aproveitamento dos pés para consumo humano, uma vez que este produto não apresentará lesões inflamatórias e contaminação microbiana importantes.

\section{REFERÊNCIAS}

BEAN, C.; JACOBSON, J.; RYAN S. USDA Foreign Agricultural Service. GAIN Report CH7006: China, Peoples Republic of Poultry and Products Chicken Paw, Wing and Wing tip Exports to China 2007. Global Agriculture Information Network, 2007. Available in: <https://apps.fas.usda.gov/gainfiles/200702/1462 80147.pdf>. Accessed in: 05 nov. 2016.

BERG C.C. Pododermatitis and hock burn in broiler chickens. In: WEEKS, C.A. BUTTERWORTH, A. Measuring and auditing broiler welfare. Reino Unido: CABI Publishing, 2004. p.37-50.

BILGILI, S.F.; HESS, J.B.; BLAKE, J.P. et al. Influence of bedding material on footpad dermatitis in broiler chickens. J. Appl. Poult. Res., v.18, p.583-589, 2009.

BRASIL. Ministério da Agricultura. Circular $N^{\circ}$ 599/2010/CGPE/DIPOA. HONG KONGExportação de cortes congelados de frango- pés. Brasília, 29 de julho de 2010.

BRASIL. Ministério da Agricultura. Portaria $\mathrm{n}^{\circ} 210$, de 10 de novembro de 1998. Aprovar o Regulamento Técnico da Inspeção Tecnológica e Higiênico-Sanitária de Carne de Aves. Diário Oficial da União, Brasília, DF, 26 nov. 1998. 
BRIZIO, A.P.D.R.; SALLES, B.P.; PRENTICE, C. Avaliação microbiológica de pés de frango destinados ao consumo humano. Semin. Ciênc. Agrár., v.34, p.2847-2852, 2013.

CHON, J.W.; JUNG, H.I.; KUK, M. et al. Microbiological evaluation of pork and chicken by-products in South Korea. J. Food Protect., v.79, p.715-722, 2016.

CRESPO, R.; SHIVAPRASAD, H.L. Developmental, metabolic, and other noninfectious disorders. In: SAIF Y.M. (Ed.) Diseases of poultry. 11.ed. Iowa: State Press, 2003. 1231p.

DOWNES, F.P.; ITO, K.F. Compendium of methods for the microbiological examination of foods. 4.ed. EUA: Sheridan Books, 2001. 618p.

GREENE, J.A.; MCCRACKEN, R.M.; EVANS, R.T. Contact dermatitis of broilers - clinical and pathological findings. Avian Path., v.14, p.23-38, 1985.

LORM, A. Welfare Quality ${ }^{\circledR}$ assessment protocol for poultry. Holanda: ASG Veehouderij BV, 2009. 119p.

MARTLAND, M.F. Ulcerative dermatitis in broiler chickens: the effects of wet litter. Avian Path., v.14, p.353-364, 1985.

MAYNE, R.K. A review of the aetiology and possible causative factors of foot pad dermatitis in growing turkey and broilers. World's Poult. Sci. J., v.61, p.256-265, 2005.

NAIRN, N.E.; WATSON, A.R.A. Leg weakness of poultry: A clinical and pathological characterization. Aust. Vet. J., v.48, p.645-656, 1972.

PAGAZAURTUNDUA, A.; WARRISS, P.D. Levels of foot pad dermatitis in broiler chickens reared in 5 different systems. Br. Poult. Sci., v.47, p.529-532, 2006.

MULDER, N.D. Poultry quaterly Q3 2017. Raboresearch, 2017. Available in: $<$ https://services.rabobank.com/publicationservic e/download/publication/token/CHazyuaaIMceVE sZ95dK>. Accessed in: 05 nov. 2017.
SANTOS, F.F.; AQUINO, M.H.C.; NASIMENTO, E.R. et al. Chicken feet bacteriological quality at 4 steps of technological processing. Poult. Sci., v.90, p.2864-2868, 2011.

SANTOS, R.L.; NUNES, V.A.; BAIÃO, N.C. Pododermatite de contato em frangos de corte. Arq. Bras. Med. Vet. Zootec., v.54, p.655-658, 2002.

TAVARES, G.C.M.B.; ARAÚJO, A.H.B.; COLNAGO, G.L. et al. Composição química e digestibilidade de partes e subprodutos de aves nas formas crua e cozida para cães. Arq. Bras. Med. Vet. Zootec., v.62, p.453-459, 2010.

THRUSFIELD, M.V. Veterinary epidemiology. 2.ed. Edinburgh: Blackwell, 1995. 483p.

UNITED STATES DEPARTMENT OF AGRICULTURE (USDA). Foreign Agricultural Service. Global Agricultural Trade System. Disponível em: <https://apps.fas.usda.gov/gats/default.aspx>. Acessado em: 23 fev. 2018.

VANDERHASSELT, R.F.; SPRENGER, M.; DUCHATEAU, L. et al. Automated assessment of footpad dermatitis in broiler chickens at the slaughter-line: evaluation and correspondence with human expert scores. Poult. Sci., v.92, p.1218, 2013.

WHITEHEAD, C.C.; BANNISTER, D.W. Aspects of metabolism related to the occurrence of skin lesions in biotin-deficient chicks. $\mathrm{Br}$. Poult. Sci., v.22, p.467-472, 1981.

WOOSLEY, M.; BECKMAN, C.; ZHANG, J. USDA. Foreign agricultural service. GAIN report number $\mathrm{CH} 11043$ : poultry and products annual 2011. Global Agricult. Inf. Network, 2011. Available in <https://gain.fas.usda.gov/Recent\%20GAIN\%20 Publications/Poultry\%20and\%20Products\%20An nual_Beijing_China\%20-

\%20Peoples\%20Republic\%20of_9-192011.pdf>. Accessed in: 05 nov. 2016. 